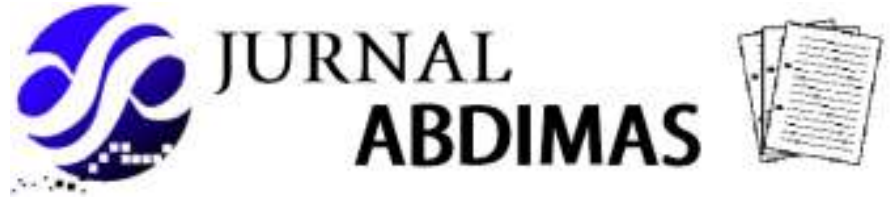

\section{Time Management Skills For Entrepreneur Success}

\author{
${ }^{1}$ Riyan Sisiawan Putra, ${ }^{2}$ Ubaidillah Zuhdi \\ ${ }^{1,2}$ Universitas Nahdlatul Ulama Surabaya
}

\author{
Alamat Surat \\ Email: riyan_sisiawan@unusa.ac.id*, ubaidillah.zuhdi@unusa.ac.id \\ Article History: \\ Diajukan: 20 Januari 2021; Direvisi: 2 Februari 2021; Accepted: 5 Februari 2021
}

\begin{abstract}
ABSTRAK
Kegiatan Waktu sangat penting karena waktu yang biasa terbuang sia-sia bisa jadi merukapan waktu yang berguna bahkan bisa menjadi peluang yang menghasilkan uang. Dalam pengabdian ini kami akan mengajarkan bagaimana cara mengatur waktu dengan baik sehingga nantinya para pelaku usaha bisa terbiasa menata waktu dan mencari peluang sebaik mungkin. Dengan menggunakan metode seminar online kami mendapatkan hasil :

1. Memahami tentang wirausaha kreatif dan pentingnya menjadi seorang wirausaha

2. Berkeinginan untuk membuka/merintis usaha baru

3. Mempunyai ide-ide baru untuk usaha kreatif

Dengan dilaksanakannya kegiatan pengabdian masyarakat ini, diharapkan dapat membantu para pengusaha maupun masyarakat sekitar untuk berkembang dalam kondisi yang sedang bermasalah dengan baik.
\end{abstract}

Kata kunci: Manajemen waktu, Peluang, Dampak, Usaha Kreatif

ABSTRACT

Activity Time is very important because time that would normally be wasted can be used as a useful time or even a money-making opportunity. In this service, we will teach you how to manage time properly so that later business people can get used to managing time and looking for the best possible opportunities. By using the online seminar method, we get the following results:

1. Understand about creative entrepreneurship and the importance of being an entrepreneur

2. Desire to open / start a new business

3. Have new ideas for creative endeavors

By carrying out this community service activity, it is hoped that it can help entrepreneurs and the surrounding community to develop well in troubled conditions.

Keywords: Time management, Opportunity, Impact, Creative Endeavors

\section{PENDAHULUAN}

Pengabdian masyarakat ini yang akan dilakukan adalah dengan menggunakan Aplikasi Zoom. Pengabdian masyarakat secara virtual ini dilakukan dengan pertimbangan beberapa hal, salah satu hal yang paling utama adalah adanya pandemi Covid-19 yang mengharuskan menjaga jarak dan melakukan WFH. Kegiatan ini dihadiri oleh beberapa mahasiswa umum serta para pelaku usaha yang ada diseluruh Indonesia.

Secara umum, para pelaku usaha merupakan suatu penggerak untuk meningkatkatkan perekonomian negara, dan juga bisa menjadi ladang lowongan pekerjaan untuk masyakarat di Indonesia. Maka dari itu peran pelaku usaha sangat di butuhkan di Indoensia untuk membantuh kesejahteraan masyakat Indonesia dan sebagai pembelajaran kepada generasi muda untuk terus bisa memikirkan hal-hal baru yang di manfaatkan sebagai peluang usaha. Banyak faktor yang memperngaruhi keberhasilan para pelaku usaha, salah satunya adalah Manajemen waktu. 
Salah satu pelaku usaha ini adalah Rubylicious. Rubylicious merupakan salah satu toko baju yang terletak di Surabaya Timur. usaha ini menjual cukup banyak pakaian wanita, tas, sepatu, pernak pernik, dll. Omzet yang didapat bisa mencapai 5 juta per bulan dan butik ini telah mempunyai empat cabang yang masing-masing memiliki 6 pegawai. Butik ini berlokasi di Jl. Arief Rahman Hakim No. 36B, Klampis Ngasem, Kec. Sukolilo, Kota Surabaya, Jawa Timur. Para pelaku usaha seperti Rubylicios ini sangat membutuhkan manajemen waktu dengan baik, agar sistem yang ada salam manajemen butik berjalan dengan lancar dan bisa memanfaatkan peluang dengan baik. Apabila para pelaku usaha tidak bisa memanfaatkan waktu dengan baik maka akan banyak peluang yang terbuang percuma sehingga bisa menyebabkan usaha yang dimiliki gulung tikar.

Manajemen waktu sendiri adalah pencapaian sasaran utama kehidupan sebagai hasil dari menyisihkan kegiatan-kegiatan tidak berarti yang sering kali justru banyak memakan waktu ( Taylor, Harold. L. Manajemen Waktu Suatu Pedoman Pengelolaan Waktu yang Efektif dan Produktif. Jakarta: Binarupa Aksara, 1990). Manajemen waktu merupakan perencanaan, pengorganisasian, pengetatan dan pengawasan produktifitas waktu. Efektifitas terlihat dari tercapainya tujuan menggunakan waktu yang telah ditetapkan sebelumnya. Efisien bermakna pengurangan waktu yang ditentukan dan investasi menggunakan waktu yang ada. Manajemen waktu bertujuan pada produktivitas yang berarti rasio output dengan input. Manajemen waktu adalah kemampuan untuk mengalokasikan waktu dan sumber daya untuk mencapat tujuan. Menciptakan keseimbangan antara pekerjaan dan kehidupan pribadi. Konsentrasi pada hasil dan bukan sekedar menyibukkan diri. Manajemen waktu bukan hanya mengacu kepada pengelolaan waktu, tetapi lebih cenderung pada bagaimana memanfaatkan waktu. Individu yang mampu mengelola waktu akan menentukan prioritas dari berbagai tugas yang dihadapi, fokus waktu dan energi pada tugas yang penting terlebih dahulu. (Sandra, Kusnul ika \& M. As'ad Djalali. Manajemen Waktu, Efikas-Diri dan Prokrastinasi. (Surabaya: Jurnal Psikologi Indonesia, Universitas 17 Agustus 1945,2013), 2(3), 217-222 ).

Menurut Kusashi (dalam Adebisi, 2013) menunda adanya pengambilan keputusan terhadap suatu masalah dapat menaikkan biaya perusahaan menjadi lebih mahal. Sehingga perlu adanya pengoptimalan waktu yang harus dilakukan oleh perusahaan. Dengan begitu time management ini penting untuk menjadikan perusahaan lebih produktif, kreatif, dan meminimalisir biaya dalam efisiensi kinerja perusahaan. Menurut Claessense, et al (2007) penggunaan teknik time management akan berhubungan langsung terhadap kinerja, kepuasan, serta dapat mengurangi tingkat kecemasaan. Adanya manajemen waktu ini sangat penting untuk keberhasilan perusahaan. Riyan sisawan (2013) menjelaskan faktor-faktor yang mempengaruhi prestasi atau keberhasilan kerja antara lain yaitu adanya kedisiplinan kerja, pencapaian target pekerjaan, semangat kerja dan kemampuan bekerjasama dengan tim. Oleh karena itu bisa diketahui bahwa faktor-faktor keberhasilan tersebut mempunyai korelasi dengan sistem manajemen waktu yang baik.

Maka dari itu untuk saat ini, para pelaku usaha membutuhkan pengetahuan lebih untuk menciptakan terobosan agar usaha mereka bisa terus maju dan lebih mengerti tentang sistem dari manajemen waktu yang baik sehingga bisa meningkatkan penghasilan dari usaha yang dimilikinya.

\section{METODE PELAKSANAAN}

Dalam kegiatan pengabdian masyarakat ini memiliki subyek pengabdian yaitu para pelaku usaha yang membutuhkan pendamping usaha untuk melakukan terobosan agar usaha mereka bisa maju. Dan kami juga bekerja sama dengan salah satu mitra yang termasuk dalam subyek pengabdian kami, yakni Rubylicious. Mitra kami berlokasi di Jl. Arief Rahman Hakim No. 36B, Klampis Ngasem, Kec. Sukolilo, Kota Surabaya. Keterlibatan mitra kami yaitu terlibat secara keseluruhan dalam program pengabdian masyarakat meliputi perumusan masalah, perencanaan program, penjadwalan kegiatan, dan pelaksanaan program.

Metode yang kami gunakan menggunakan 2 (dua) pendekatan yaitu seminar dan diskusi. Program seminar / webinar dilaksanakan kepada para pelaku usaha, berisi pemaparan materi terkait cara mengatur waktu dan mencari peluang di tengah kondisi usaha yang sedang bermasalah. Setelah materi disampaikan, dilanjutkan dengan sesi diskusi / tanya jawab agar kami mengetahui seberapa 
dalam materi yang sudah tersampaikan namun juga ada sharing pengalaman maupun permasalahan yang sering dihadapi oleh para pelaku usaha. Dan kegiatan pengabdian ini memiliki tahapan sebagai berikut:

\begin{tabular}{|c|c|}
\hline \multicolumn{2}{|c|}{ Tahap Persiapan } \\
\hline Pra-Survei & Mengidentifikasi permasalahan dan kebutuhan mitra \\
\hline $\begin{array}{c}\text { Pembentukan Tim } \\
\text { Pengabdian Masyarakat }\end{array}$ & $\begin{array}{c}\text { Pembentukan Tim disesuaikan dengan jenis kepakaran } \\
\text { untuk menyelesaikan permasalahan mitra. }\end{array}$ \\
\hline Pembuatan Proposal & $\begin{array}{c}\text { Pembuatan proposal untuk menawarkan solusi } \\
\text { permasalahan dan anggaran dana dalam pelaksanaan kegiatan } \\
\text { pengabdian masyarakat }\end{array}$ \\
\hline $\begin{array}{c}\text { Koordinasi Tim dan } \\
\text { Mitra }\end{array}$ & $\begin{array}{c}\text { Perencanaan pelaksanaan program secara konseptual, } \\
\text { operasional dan disesuaikan dengan job desc nya masing- } \\
\text { masing anatara Tim dan Mitra. }\end{array}$ \\
\hline $\begin{array}{c}\text { Persiapan bahan } \\
\text { Pengabdian Masyarakat }\end{array}$ & Pembuatan materi kegiatan \\
\hline \multicolumn{2}{|c|}{ (Kegiatan Pengabdian Masyarakat Dillaksanakan secara daring lewat aplikasi } \\
ZOOM)
\end{tabular}

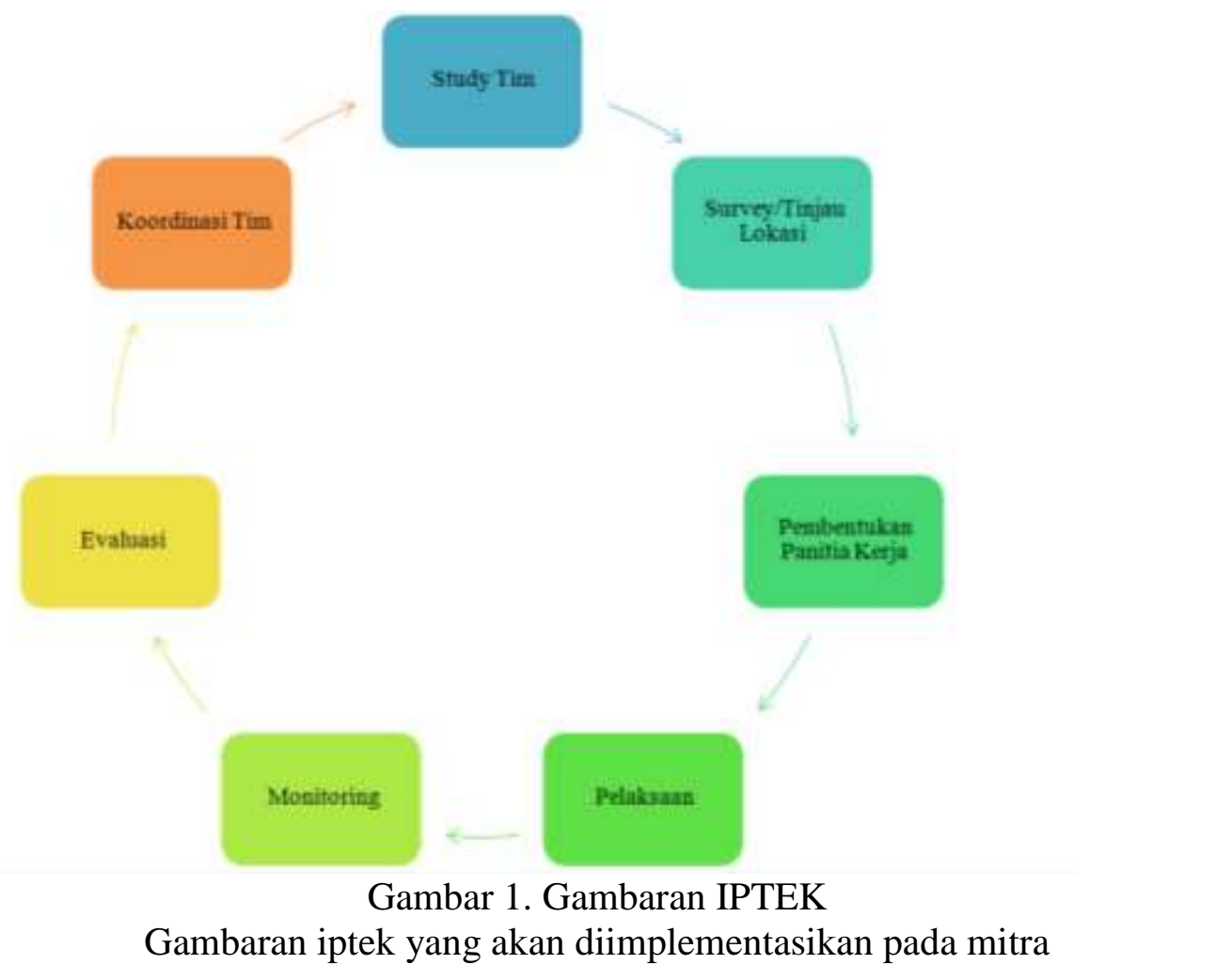




\section{HASIL KEGIATAN}

Kegiatan pengabdian kepada masyarakat tentang manajemen waktu yang baik pada para pengusaha dan mahasiswa di seluruh Indonesia, kegiatan ini dilaksanakan selama satu hari pada tanggal 4 Juli 2020. Pemateri memberikan materi tentang pentingnya manjemen waktu dengan baik. Hal ini dilakukan dengan memberikan pemahaman lebih tentang bagaimana memanajemen waktu yang baik untuk bisa memanfaatkan peluang yang ada dengan sebaik mungkin. Dengan adanya kegiatan program pengabdian masyarakat bidang manajemen oleh Fakultas Ekonomi dan Bisnis Universitas Nahdlatul Ulama Surabaya ini diharapkan mampu menyelesaikan permasalahan untuk menumbuhkan jiwa wirausaha yang bisa memanfaatkan peluang yang ada dengan manjemen waktu yang baik dan teratur kepada wirausahawan dan calon wirausahawan. Jika hal itu berjalan dengan lancar dan sistem manjemen waktu yang baik bisa di terapkan dalam kehidupan sehari-hari maka individu tersebut akan bisa mencapai produktifitas dan efisien yang lebih besar dan memiliki reputasi profesional yang lebih baik.

Para pelaku usaha ini sebenarnya banyak yang memiliki kemauan untuk menambah pengetahuan dan pemahaman mengenai manajemen waktu dengan baik. Hal ini dapat dilihat dari partisipasi para pelaku usaha dan mahsiswa di seluruh Indonesia untuk mengikuti webinar yang diadakan tentang manjemen waktu dan terdapat banyak pertanyaan dalam sesi tanya jawab. Para pelaku usaha dan calon wirausahawan juga banyak yang memiliki minat dan keinginan untuk memperoleh informasi dan mendapatkan pengetahuan tentang dasar-dasar mnajemen waktu, manfaat yang bisa di ambil dan cara pelaksanaan yang benar sehingga bisa menerapkannya dengan baik dalam kehidupan sehari-hari. Kegiatan pengabdian masyarakat yang dilakukan oleh Fakultas Ekonomi dan Bisni ini di sambut baik oleh peserta dan para peserta juga meminta supaya kegiatan pengabdian masyarakat ini didakan secara berkelanjutan untuk mengadakan seperti pelatihan mengenai manjemen waktu yang baik sehingga para peserta merasakan manfaatnya.

\section{KESIMPULAN}

Berdasarkan kegiatan yang telah dilaksanakan oleh Tim Pengabdian Kepada masyarakat untuk pelaku usaha dan calon pelaku usaha serta para mahasiswa dapat disimpulkan bahwa pertama, kegiatan pengabdian kepada masyarakat mengenai manjemen waktu dengan baik untuk membantu menciptakan pengusaha yang sukses berjalan dengan baik sesuai dengan rencana awal.

Kedua kegiatan pengabdian kepada masyarakat untuk pelaku usaha dan calon pelaku usaha serta para mahasiswa ini berisi tentang pemapamaran materi oleh Tim pengabdian masyarakata dalan dilanjutkan tanya jawab dan diskusi oleh peserta kepada pemateri, sehingga tidak hanya berbagi ilmu saja akan tetapi bisa sharing mengenai permasalahan-permasalahan yang sudah dihadapai. Ketiga untuk memotivasi para pelaku usaha dan calon pelaku usaha serta para mahasiswa untuk menjadi seorang wirausaha yang profesional dan dapat memanajemen waktu dengan baik.

Keempat kegiatan pengabdian kepada masyarakat mengenai pemberdayaan usaha ekonomi yang mengedepankan manjemen waktu dengan baik ini memiliki kontribusi besar besar untuk masyarakat disekitar, karena kegiatan pengabdian masyarakat ini bertujuan untuk menumbuhkan jiwa profesionalitas yang baik dalam berwirausaha dan dapat memanajemen waktu dengan baik, maka para pelaku usaha juga bisa berperan untuk mengurangi pengangguran karena usaha yang sukses di pengaruhi dengan hal utama yaitu manajemen waktu yang baik.

Kegiatan pengabdian kepada masyarakat dengan memberikan materi dan diskusi ini menjadi jembatan bagi perguruan tinggi khususnya UNUSA dengan masyarakat dalam mentransfer ilmu dan pengetahuan yang sudah luas sehingga dapat langsung dirasakan oleh para peserta.

\section{PENGAKUAN}

Alhamdulillah, puji syukur kami panjatkan kehadirat Allah SWT atas Karunia-Nya, penyusunan laporan kegiatan pengabdian masyarakat dengan judul "Time Management Skills For Entrepreneur Success" ini dapat terselesaikan. Laporan kegiatan pengabdian masyarakat ini berisikan mengenai hasil kegiatan dosen dan mahasiswa dalam melakukan sosialisasi kesesuaian hasil riset 
untuk publikasi ke jurnal bereputasi via Online melalui aplikasi zoom dan media Youtube. Kegiatan ini dilakukan dengan tujuan untuk meningkatkan wawasan para pelaku usaha dalam mengatur waktu dengan baik sehingga nantinya para pelaku usaha bisa terbiasa menata waktu dan mencari peluang sebaik mungkin. Dengan terselesaikannya laporan kegiatan pengabdian masyarakat ini, perkenankan saya mengucapkan terima kasih yang sebesar-besarnya kepada:

1. Prof. Dr. Ir. Achmad Jazidie, M.Eng selaku Rektor Universitas Nahdlatul Ulama Surabaya.

2. Dr. Istas Pratomo, S.T., M.T selaku Ketua Lembaga Penelitian dan Pengabdian Masyarakat Universitas Nahdlatul Ulama Surabaya.

3. Dr. M. Yusak Anshori, drs., M.M. selaku dekan Fakultas Ekonomi dan Bisnis Nahdlatul Ulama Surabaya.

4. Riyan Sisiawan Putra., S.E., M.SM selaku Ketua Program Studi S1 Manajemen Universitas Nahdltul Ulama Surabaya

5. Para anggota pelaksana pengabdian masyarakat yang terlibat dalam pelaksanaan pengabdian masyarakat.

6. Para mahasiswa yang terlibat dalam pelaksanaan pengabdian masyarakat.

\section{DAFTAR PUSTAKA}

Adebisi, J. F. (2013). Time management practices and its effect on business performance. Canadian Social Science, 9(1). Canadian Research \& Development Center of Sciences and Cultures, Montreal, Canada

Claessens, et al. (2007). A review of the time management literature. Personnel Review, 36(2), 255 275.

Putra, R. S. (2013). Pengaruh Budaya Perusahaan Terhadap Prestasi Kerja Karyawan PT. Pembangkitan Jawa-Bali Surabaya Unit Pelayanan Pemeliharaan. Journal Vol.15 No.2 (131140)

Sandra, Kusnul ika \& M. As'ad Djalali. Manajemen Waktu, Efikas-Diri dan Prokrastinasi. (Surabaya: Jurnal Psikologi Indonesia, Universitas 17 Agustus 1945, 2013), 2(3), 217-222

Taylor, Harold. L. Manajemen Waktu Suatu Pedoman Pengelolaan Waktu yang Efektif dan Produktif. Jakarta: Binarupa Aksara, 1990

Wijoyo, H., \& Haudi, H. (2021, January). PENYULUHAN TEKNIK PEMASARAN KERUPUK RASA JENGKOL "DONG DONG SNACK" PEKANBARU. In PROSIDING SENANTIAS: Seminar Nasional Hasil Penelitian dan Pengabdian kepada Masyarakat (Vol. 1, No. 1, pp. 643-650).

Wijoyo, H. (2020). Socialization Of The Accreditation Asessment System (SISPENA) Of The National Accreditation Board For Early Childhood Education (PAUD) And Non Formal Education (PNF) In Bengkalis, Riau Province. Jurnal Humanities Pengabdian Kepada Masyarakat, 1(1), 103-111.

Wijoyo, H., Haudi, H., Ariyanto, A., Sunarsi, D., \& Akbar, M. F. (2020). Pelatihan Pembuatan Konten Digital Marketing Dalam Meningkatkan Kompetensi Mahasiswa (Pengabdian Kepada Masyarakat Kerjasama Antar Kampus). IKRA-ITH ABDIMAS, 3(3), 169-175.

Wijoyo, H. (2020). Sosialiasi Sistem Penilaian Akreditasi (SisPenA) Badan Akreditasi Nasional Pendidikan Anak Usia Dini (PAUD) dan Pendidikan Non Formal (PNF) di Kecamatan Bantan, Kabupaten Bengkalis, Propinsi Riau. ARBITRASE: Journal of Economics and Accounting, 1(1), 7-10. 